\title{
Can the Stepping Stone Enhance the Establishment, Competition and Distribution of Sown Grassland Species during Recovery on Ex-Arable Lands?
}

\author{
Jimmy Edgar Alvarez-Diaz1, María del Carmen Santa-Regina², Ignacio Santa-Regina3 ${ }^{*}$ \\ ${ }^{1}$ Universidad de Antioquía, Medellín, Colombia \\ ${ }^{2}$ Instituto Arcipreste de Hita, Madrid, Spain \\ ${ }^{3}$ IRNASA-CSIC, Salamanca, Spain \\ Email: *ignacio.santaregina@irnasa.csic.es
}

How to cite this paper: Alvarez-Diaz, J.E., Santa-Regina, M.C. and Santa-Regina, I. (2016) Can the Stepping Stone Enhance the Establishment, Competition and Distribution of Sown Grassland Species during Recovery on Ex-Arable Lands? Open Journat of Ecology, 6, 579-597.

http://dx.doi.org/10.4236/oje.2016.610056

Received: July 27,2016

Accepted: September 13, 2016

Published: September 16, 2016

Copyright (c) 2016 by authors and Scientific Research Publishing Inc. This work is licensed under the Creative Commons Attribution International License (CC BY 4.0).

http://creativecommons.org/licenses/by/4.0/

\begin{abstract}
Most diversity restoration projects are not to improve diversity per se, but rather to enhance the presence and abundance of species that are characteristic of reference or target community. The use of Bromus inermis suppresses annual noxious grasses and increases the control of other-forb group although these species are also noxious weeds; these may be substituted with another perennial species of the same functional group all through the whole experimental period, as it occurs with other perennialforb Carduus tenuifolius. A field experiment was conducted on abandoned arable land with sown low and high diversity treatments and natural colonization following typical farming practice for the site. Experimental plots were installed on former agricultural land that had been cropped with (a rotation of) monocultures until the end of 1995. The experiment was organized according to a block design with five replicate blocks. An opposite trend was performed among the colonizer species, because the colonizer grasses were relegated by the high dominance of sown grasses. But at the same time, the sown grasses facilitated the dominance of other colonizer-forbs species; therefore its functional replacement in the community due to sown effect was again tested. However, in natural conditions the other-forbs group was the dominant group, without taking into account the stepping-stone treatment and there was also a functional change of dominance. Our study has demonstrated the restoration effectiveness of species richness at abandoned arable land and may be enhanced by sowing late successional species.
\end{abstract}

\section{Keywords}

Colonizer Species, Ecosystem Functioning, Invasiveness, Noxious Weeds, 
Restoration, Sowing Experiment, Species Richness, Stepping Stone

\section{Introduction}

Various empirical studies [1] [2] have shown that ecosystem function is mainly a consequence of the prevailing strategies of constituent species, in interaction with the abiotic environment. Even some of the experimental effects that are attributed to diversity are probably a consequence of the effect of abiotic conditions and species ecophysiology [2] [3]. Nevertheless, the fact that species life histories are more important than diversity per se does not mean that diversity has no effect on ecosystem function. Indeed, the majority of ecologists are convinced about the importance of diversity for ecosystem processes [4]. The evidence supporting the diversity effect is now the focus of novel ecological research and is hotly debated [2] [5] [6].

Plant species differ in their ability to grow under different physical/chemical conditions that vary spatially, competing for several resources at any given spatial location. The most widely cited mechanisms for increased competitive exclusion at high productivities are based on the fact that higher productivities will reduce spatial heterogeneity in the relative supplies of different resources, thus reducing the number of species that are able to coexist. [7] introduced a model based on the assumption that the two essential resources are mineral nutrients and light.

Disturbances are one of the important sources of spatial and temporal variability in communities. They are now widely recognized as a key element in community dynamics [8]. Indeed, disturbances can contribute to the maintenance of diversity in two ways: firstly, they contribute to the maintenance of species richness [9] [10]; secondly, they can increase spatial heterogeneity [11]. Disturbances occur at a variety of scales within a landscape [12]. Local disturbances in particular are important component of the dynamics of grasslands under a variety of climates [13] [14].

The trend observed in disturbances may be explained by the persistence of species of younger stages [15]. Disturbances promoted the colonization by therophytes but did not seem to affect the persistence of phanerophytes. This is probably linked with the fact that many species are able to easily resprout and expand vegetatively. Many species would also remain in the soil seed bank and reappear after disturbance. Such characteristics give these communities a rapid resilience [16]. Mediterranean old fields have high species diversity [17] [18]. These species diversity is maintained by the recurrence of small-scale disturbances which facilitate the coexistence of species with different regeneration niches [19].

Biological invasions are recognized as major environmental problems and one of the major threats to biodiversity [20] [21]. The success and impacts of alien species depends on their biological attributes, the environmental characteristics of the invaded ecosystem and the biotic interactions with the receptive community. When an alien plant species is introduced, competition for limiting resources is probably the first in- 
teraction the species has with the recipient community. Interspecific competition is considered as one of the most important processes determining the likelihood of plant invasion [22], as suggested by the important role of disturbance, which decreases competition and increases the probability of invasion. High competition ability of alien species has been stated as a key factor promoting successful invasive potential [21], and competitive exclusion by native plant species seems to be a major force resisting exotic invasions [23].

A number of rather short-term experiments [2] [24]-[26] have indicated that, on average, species-rich mixtures are more productive and also more efficient in suppressing weed species and preventing further colonization than species-poor mixtures [24] [27] [28], with some low diversity mixtures being as productive and as effective as the high diversity mixtures; those successful low diversity mixtures are usually composed of species dominating the high diversity mixtures [2]. Several experiments studying the effects of sowing species mixtures on vegetation development have been conducted for a limited period of time, and some were accompanied by weeding [29]. While weeding is a useful tool to keep restricted sets of species in experimental plots, it is obviously not a feasible type of management practice and it allow weeds to become established after some years of hand-weeding which completely misses out the effects of pioneer plant species on plant community development after land abandonment. It is also difficult to extrapolate the long-term effects of sowing from short-term experiments. For example, the chalk-grassland experiment of Pakeman et al. [30] shows that the system changes even 25 years after establishment. Moreover, some short-term 'biodiversity' effects disappeared after cessation of weeding [31]. Therefore, we analyzed and present effects of the sowing treatments and report on eight years of community development.

The following questions were addressed: How successful is the establishment competition and distribution of sown grassland species on ex-arable lands after the introduction of stepping stone, and if exotics will be more likely to invade areas with low diversity species than areas with high diversity species. The main aim of this study was to elucidate the patterns of diversity in plant species and communities after application of stepping stone treatment.

\section{Materials and Methods}

\subsection{Site Description}

The study area was located at $850 \mathrm{~m}$ a.s.l., $15 \mathrm{~km}$ to the west of Salamanca city, Spain, (its coordinates: $40^{\circ} 54^{\prime} 00^{\prime \prime} \mathrm{N}, 5^{\circ} 45^{\prime} 30^{\prime \prime} \mathrm{W}$ ), where a 1 ha experimental plot was chosen at the Muñovela experimental farm (C.S.I.C) (Figure 1). The plot is edaphically homogenous, with a dehesa-like woodland. Previously, it was heavily grazed although it is now fenced off to prevent the access of domestic animals.

The climate of the zone features rainy winters and hot summers and may be classified as semi-arid Mediterranean $\left(\mathrm{C}_{1} \mathrm{~B}_{1}{ }_{1} \mathrm{~S}_{2} \mathrm{~b}_{4}{ }_{4}\right)$. Long-term mean rainfall and temperature have mean values of $500 \mathrm{~mm}$ and $12.3^{\circ} \mathrm{C}$, November being the rainiest month (99 $\mathrm{mm})$ and July the driest $(17 \mathrm{~mm})$. January is normally the coldest month $\left(0.8^{\circ} \mathrm{C}\right)$. 


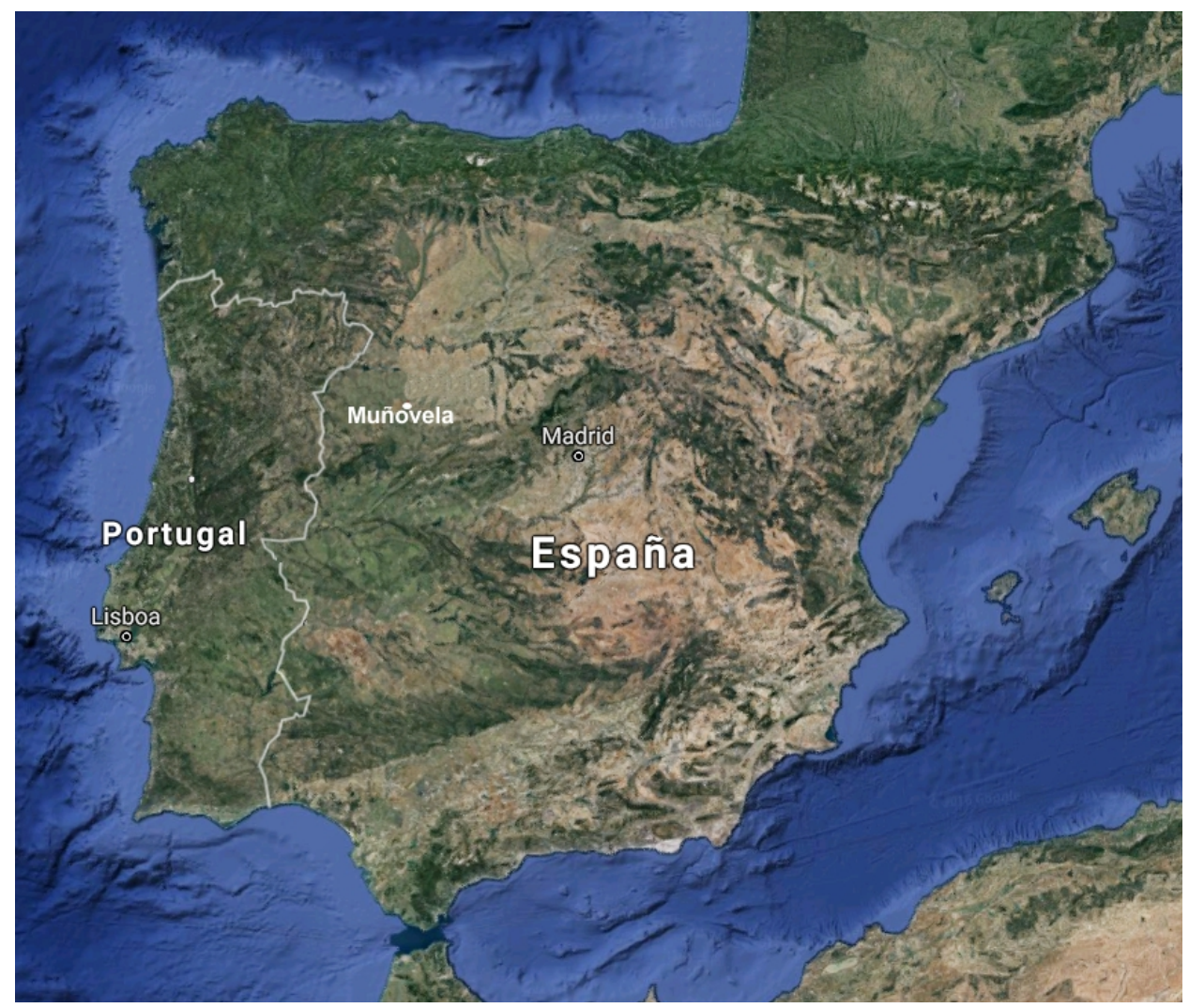

Figure 1. Map of the study area.

The tree covering comprises Quercus rotundifolia Lam, with a density of 98 trees $\mathrm{ha}^{-1}$, a mean height of $5.9 \mathrm{~m}$ and mean diameter of $29.1 \mathrm{~cm}$. Chorologically, the area lies in the Mediterranean Region, Carpetano-Ibérico-Leonesa province, Salmantino sector, Genisto hystricis-Querceto-rotundifoliae sigmetum series. The estimated mean age of the trees was 150 years. Other characteristic species defining the series are: Doryncium pentaphyllum, Thymus zygis, T. mastichina and Crataegus monogyna.

Plant identification method uses identification "keys". These tools are found in many plant manuals or plant identification or field guides.

The soil is a chromic luvisol [32], developed over red clays and Miocene conglomerates. Soil texture A/B is loam/clay, the slope of the plot is $2 \%$, soil pH: $6.23, \mathrm{C} / \mathrm{N}: 6.25, \mathrm{P}$ (ppm): 30.5, K (ppm): 263, Ca (ppm): 1600.

A field experiment was conducted on abandoned arable land with sown low and high diversity treatments and natural colonization following typical farming practice for the site. In April-May 1996, experimental plots were installed on former agricultural land that had been cropped with (a rotation of) monocultures until the end of 1995. The experiment was organised according to a block design with five replicate blocks. Within each block, four plots measuring $2 \times 2 \mathrm{~m}$ were marked out and each of the three treatments was randomly assigned to one plot. All plots were separated by border rows of 1 $\mathrm{m}$. The three treatments (LD-low diversity sown species, HD-high diversity sown species and NC-natural colonization,) were randomly allocated to the plots in each block. 
This experiment try to provide colonist organisms from later successional stage by the inoculation of soil from a nearby holm oak forest, and inserting turf vegetation monoliths from the same holm oak forest into the plots. This was made on half of thirty $2 \times 2$ $\mathrm{m}$ plots on the following treatments: Natural colonization (codes 1 and 4), low diversity (codes 2 and 5) and high diversity (codes 3 and 6). The assay had also five replicates (Figure 2).

As the initial vegetation development at abandoned land is usually highly unstable and unpredictable, late-successional types of functional groups of plants were experimentally sown in both low and high diversity mixture. Based on the specific characteristics of plants, the functional groups most widely recognised in tempered grassland communities and used in this study are 1) grasses, 2) legumes and 3) other forbs. The low and high diversity mixtures consisted of the same amounts of seed (grasses: 2500 seeds $\mathrm{m}^{-2}$, legumes: 500 seeds $\mathrm{m}^{-2}$, and other forbs also 500 seeds $\mathrm{m}^{-2}$ ). Fifteen species (five per functional group) were sown as the high diversity sown treatment. For the low diversity sown treatment, low diversity seed mixtures (two grasses, one legume and one other-forb species) were used as random choices from the total set of plants available for each replicate in order to take into account, the sampling effects. The plant mixtures used comprised species typical of later successional stages expected (Table 1).

Fifteen plant species (five grasses, five legume and five other forb species) were sown as the high diversity treatment. To avoid confounding the species identity effect with the diversity effect each low diversity treatment was sown with a different sub-set of the 15 species used in the high diversity treatment. The low diversity subsets contained a random selection of two grasses, one legume and one forb species. Each forb and legume species was sown in a low diversity plot of one block, while each grass species was sown in two blocks. We chose grasses as potential dominant species and forb as potential

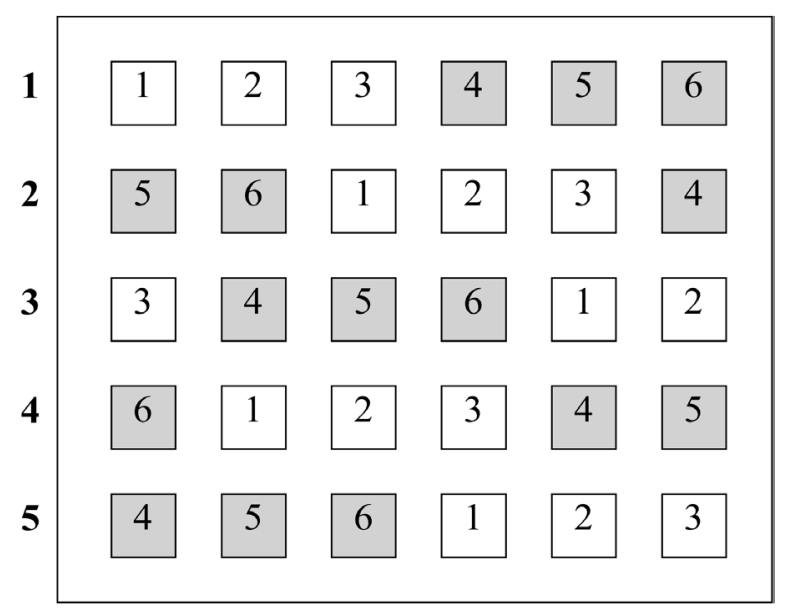

Figure 2. Experimental design of soil inoculation on six plots randomly distributed in 5 blocks. With 1 - 3 corresponding to natural colonization-NC, low diversity-LD and high diversity-HD, and $4-6$ corresponding to the same treatments with stepping stone +SS $(\square)$, and without stepping stone-SS $(\square)$. 
Table 1. Density of sown seeds (seeds $\mathrm{m}^{-2}$ ) in the five blocks of low diversity treatments (LDS1 to LDS5) and in the plots of high diversity treatments (HDS).

\begin{tabular}{|c|c|c|c|c|c|c|c|}
\hline Grasses & & LD1 & LD2 & LD3 & LD4 & LD5 & $\mathrm{HD}$ \\
\hline Bromus inermis Leyss. & BromIner & & 1250 & 1250 & & & 500 \\
\hline Festuca rubra L. & FestRubr & 1250 & & & & 1250 & 500 \\
\hline Phleum pratense $\mathrm{L}$. & PhlePrat & 1250 & 1250 & & & & 500 \\
\hline Poa pratensis $\mathrm{L}$. & PoaPrat & & & & 1250 & 1250 & 500 \\
\hline Poa trivialis $\mathrm{L}$. & PoaTriv & & & 1250 & 1250 & & 500 \\
\hline \multicolumn{8}{|l|}{ Legumes } \\
\hline Lotus corniculatus $\mathrm{L}$. & LotuCorn & 500 & & & & & 100 \\
\hline Medicago lupulina L. & MediLupu & & & 500 & & & 100 \\
\hline Trifolium fragiferum $\mathrm{L}$. & TrifFrag & & & & & 500 & 100 \\
\hline Trifolium pratense $\mathrm{L}$. & TrifPrat & & 500 & & & & 100 \\
\hline Trifolium subterraneum L. L. & TrifSubt & & & & 500 & & 100 \\
\hline \multicolumn{8}{|l|}{ Forbs } \\
\hline Achillea millefolium $\mathrm{L}$. & AchiMill & & & 500 & & & 100 \\
\hline Galium verum $\mathrm{L}$. & GaliVeru & & & & 500 & & 100 \\
\hline Matricaria chamomilla L. & MatrCham & & & & & 500 & 100 \\
\hline Plantago lanceolata $\mathrm{L}$. & PlanLanc & 500 & & & & & 100 \\
\hline Sanguisorba minor Scop. & SangMino & & 500 & & & & 100 \\
\hline
\end{tabular}

subordinate species. Legumes were regarded as separate group of forbs because of their association with nitrogen-fixing symbionts.

Fifteen plant species were sown as the high diversity treatment and five plant species were sown as the low diversity treatment is a good number indicator of three comparisons: the comparison of the average performance of LD and HD treatments, comparisons of the best LD and HD replicates, and comparison of the worst LD and HD replicates.

\subsection{Measurements}

If there is an important species identity effect, then the performance of particular LD mixtures can be predicted from the species performances in the HD plots. The following procedure was used: for each of the sown species, the average "importance" (average value of cover abundance) over all the HD plots was calculated. For each LD mixture, the total importance of its constituent species was then calculated, and this value was used as a predictor of the performance of LD mixture. The species importance in HD plots should be proportional to its competitive ability, and consequently, the total for the particular LD species combination should be a good predictor of its ability to suppress the other species (note that it is important that this total is completely independent of the performance of species in LD plots). We estimated the cover and the 
species level. This sampling has been done in all the plots, taking one sample $\left(1 \mathrm{~m}^{2}\right.$ area) from each stepping stone plot.

The presence of species arriving from later successional stage by the inoculation of soil from a nearby holm oak forest, and inserting turf vegetation monoliths from the same holm oak forest into the plots was determined in $1 \mathrm{~m}$ surface area of the each $2 \times$ $2 \mathrm{~m}$ plots.

\subsection{Statistical Analyses}

To compare the vegetation development of different sown treatments with the control treatment (natural colonization without facilitation of colonization), the Principal Response Curves (PRC) method was used; with time being the covariable and the interaction between sowing and facilitation of colonization with time as explained variables. In addition, the data of all experimental time were analyzed using an Ordination diagram (redundancy analysis; RDA): the time, sown treatments (NC, LD and HD) and soil inoculation treatments (+SS o-SS) variables were used as explained variables of community variability (Table 2). Further tests were implemented in each treatment separately to explain the effects of one treatment on the other.

1) RDA with all combined factors: In this analysis that was performed year by year, the effect of both treatments was examined simultaneously. The explained variables going into the model were done individually or by interaction between both factors.

2) RDA with the sown treatment as single used factor to assess the effect of this treatment on species composition.

3) RDA with the only treatment of soil inoculation: The sown species were excluded from this analysis, so we examined the effect of natural colonizer species (weeds).

4) RDA with the only treatment of soil inoculation, but adding the sown species: This analysis differs from the previous one in that the covers of sown species were not excluded in this analysis. This analysis differs from the previous one in that the coverage of the species planted is not excluded from the analysis. This means that the sown species were also included in the seed bank of the soil inoculated.

5) RDA to establish differences among blocks: The 5 plots of NC-SS were only permuted among themselves.

6) The variability of species composition was performed using analysis of PCA (calculated using CANOCO for Windows package [33] in all soil inoculation plots.

Table 2. Ordination diagram (redundancy analysis; RDA). A: time; T: treatments (NC, LD and HD); SS: stepping-stone; B: Block. The interactions are indicated by ${ }^{*}$. The explained variability was only estimated with the colonizer species or including the sown species (value in parentheses).

\begin{tabular}{cccc}
\hline Explained variables & Covariables & Explained variability & $P$ \\
\hline $\mathrm{A}, \mathrm{T}, \mathrm{SS}, \mathrm{T}^{\star} \mathrm{A}, \mathrm{T}^{\star} \mathrm{SS}$ & $\mathrm{B}$ & $0.437(0.457)$ & 0.002 \\
$\mathrm{~A}$ & $\mathrm{~B}, \mathrm{~T}, \mathrm{SS}$ & $0.320(0.272)$ & 0.002 \\
$\mathrm{~T}, \mathrm{~T}^{\star} \mathrm{A}$ & $\mathrm{B}, \mathrm{SS}, \mathrm{A}$ & $0.048(0.062)$ & 0.292 \\
$\mathrm{SS}, \mathrm{SS}^{\star} \mathrm{A}$ & $\mathrm{B}, \mathrm{T}, \mathrm{A}$ & $0.047(0.091)$ & 0.002 \\
\hline
\end{tabular}




\section{Results}

\subsection{Annual Performance of Stepping Stone Plots}

The principal response curves (PRC) of sown treatments and stepping stone against time is shown in Figure 3. PRC1 is the first principal component on which the species values are adjusted. In this analysis, the natural colonization without stepping stone (NC-SS) was considered as control treatment. The significance of first principal component (PRC1) was tried out by Monte Carlo permutation tests.

Seven of the fifteen sown species were successful in the stepping stone plots, with $B$. inermis being the most important between them (Figure 3). All sown species were also more abundant in the treatments where they were sown and a significant decrease of abundance in the last experimental period was established. Annual percentage of sown species separated by functional groups (grasses, other-forbs and legumes) in NC: natural colonization, LD and HD: sowing low- and high-diversity seed mixtures respectively, with stepping stone (+SS) or without stepping stone (-SS) is presented in Figure 4. Starting from 2002, the abundance of sown species decreases until $40 \%$ in both sown treatments, with or without stepping stone (Figure 4).
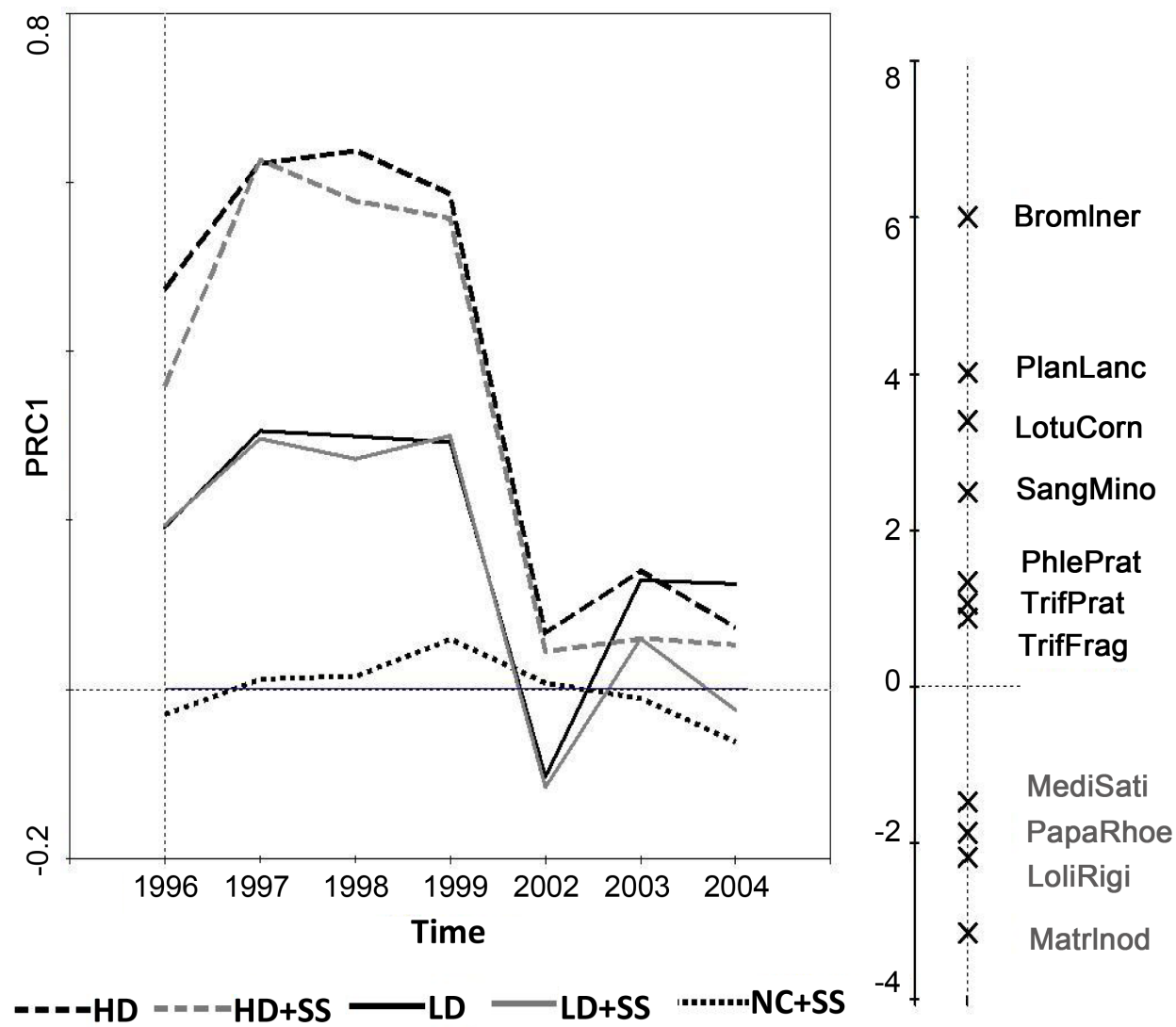

Figure 3. Principal response curves (PRC) of sown treatments and stepping stone against time. PRC1 is the first principal component on which the species values are adjusted. NC: natural colonization, LD and HD: sowing low- and high-diversity seed mixtures respectively. +SS: Stepping stone treatment. 

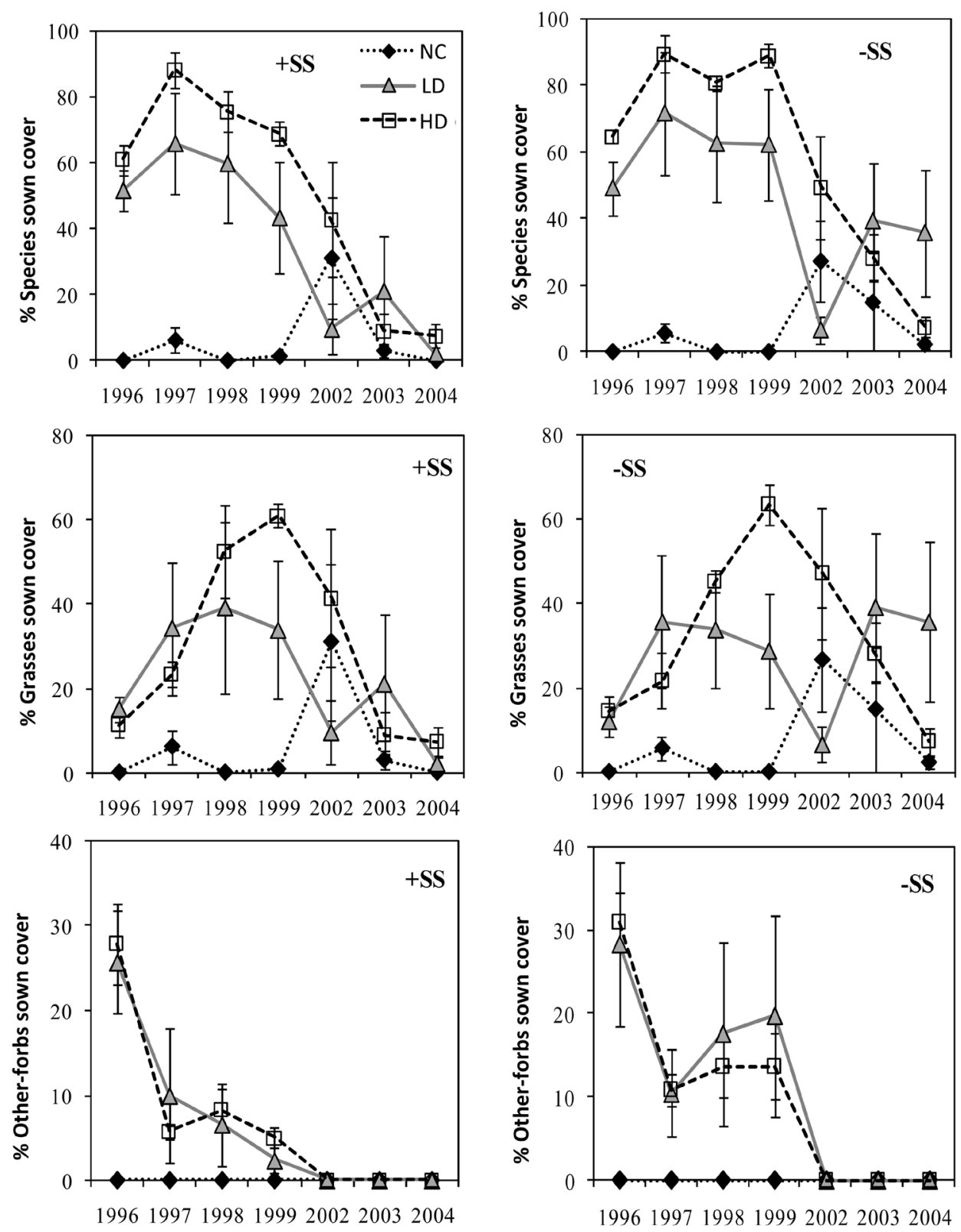

Figure 4. Annual percentage of sown species separated by functional groups (grasses, other-forbs and legumes) in NC: natural colonization, LD and HD: sowing low- and high-diversity seed mixtures respectively. Besides, each plot with stepping stone $(+\mathrm{SS})$ or without stepping stone (-SS).

Annual percentage of colonizing species, separated by functional groups (grasses, other-forbs and legumes) in NC: natural colonization, LD and HD: sowing low- and high-diversity seed mixtures respectively, with stepping stone (+SS) or without stepping stone (-SS) is indicated in Figure 5. An opposite trend was performed among the colonizer species, because the colonizer grasses were relegated by the high dominance of sown grasses. But at the same time, the sown grasses facilitated the dominance of other-forbs colonizer species; therefore, its functional replacement in the community 

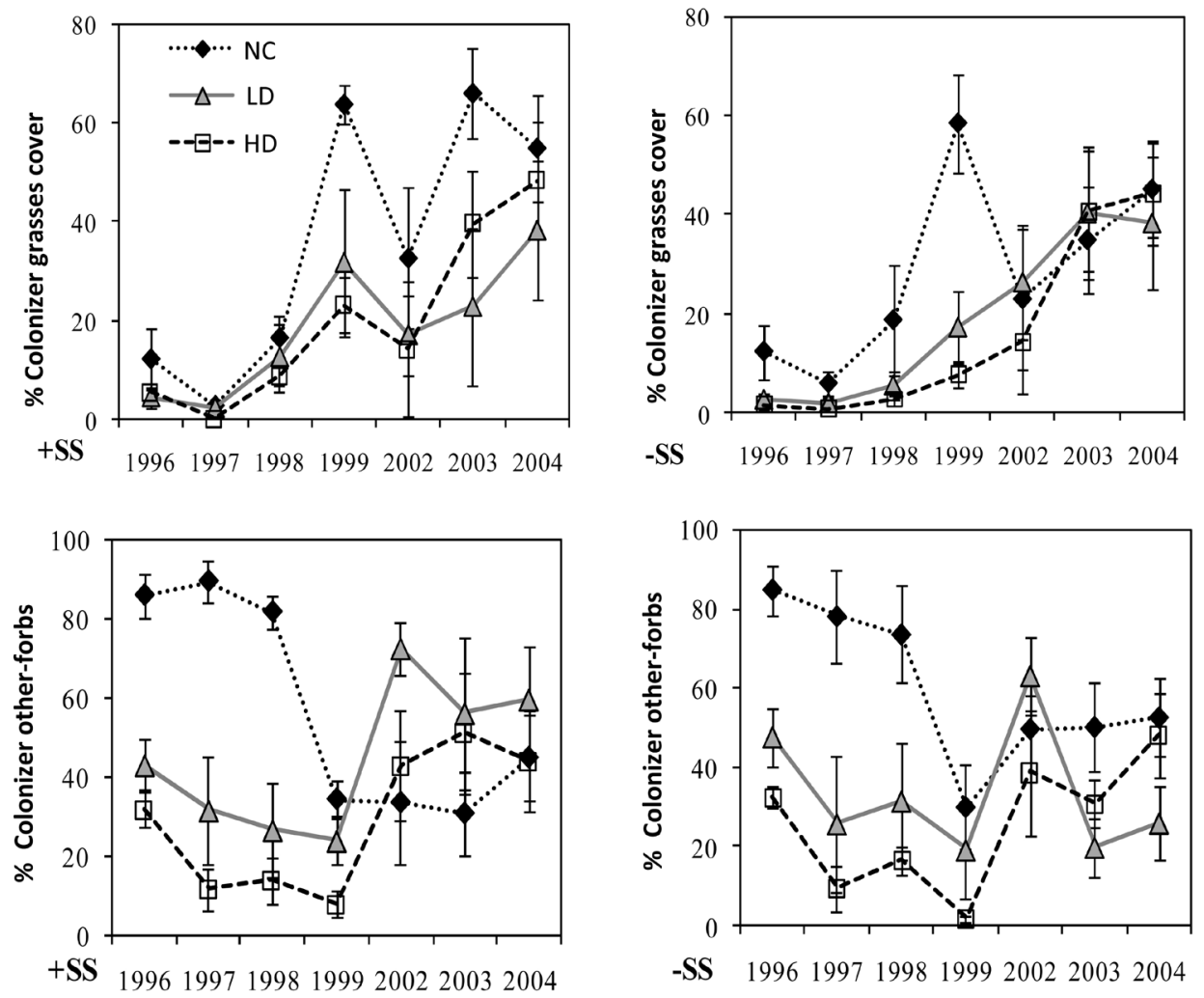

Figure 5. Annual percentage of colonizing species, separated by functional groups (grasses, other-forbs and legumes) in NC: natural colonization, LD and HD: sowing low- and high-diversity seed mixtures respectively. Besides, each plot with stepping stone (+SS) or without stepping stone $(-\mathrm{SS})$.

due to sown effect was again tested. However, in natural conditions, the other-forbs group was the dominant group; without taking into account the stepping-stone treatment and there was also a functional change of dominance at the end of 1999 (Figure 5), but at the same time, an effect of sown treatment was noted within this group, but in much smaller degree than on colonizer grasses.

\subsection{Effect on Species Composition}

Ordination diagram (redundancy analysis; RDA) was implemented to evaluate the changes of plant community in the stepping stone plots. The explained variability was only estimated with the colonizer species or including the sown species. All explained variables (time, sown treatment and stepping stone treatment) were used as exploratory to obtain the total variability of plant community and the particular analyses utilized to separate the effects of particular treatments among them. The canonical axes explain close to $43 \%$ of variability taking into account only the colonizer species, or including the sown species (45\%) (Figure 6).

Temporal changes of plant community in the plots of stepping stone are described in an Ordination diagram (redundancy analysis; RDA) (Figure 7).

The response of colonizer species to different treatment with stepping stone (+SS) or 


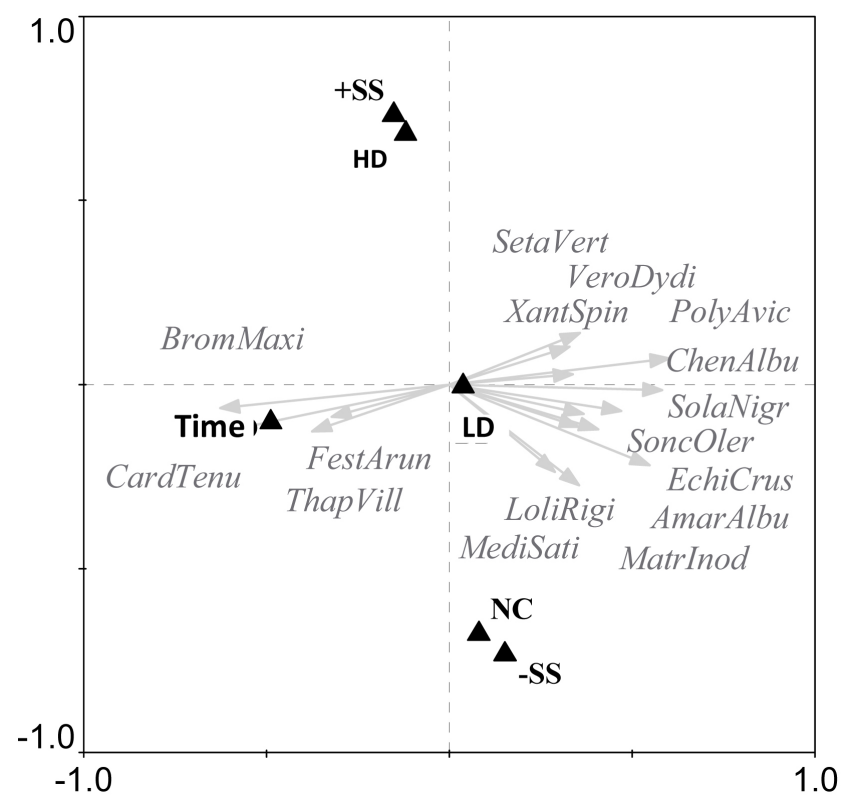

Figure 6. The changes of plant community in the plots of stepping stone are described in this Ordination diagram (redundancy analysis; RDA). NC: natural colonization, LD and HD: sowing low- and high-diversity seed mixtures respectively. Besides, each plot with stepping stone $(+\mathrm{SS})$ or without stepping stone (-SS).

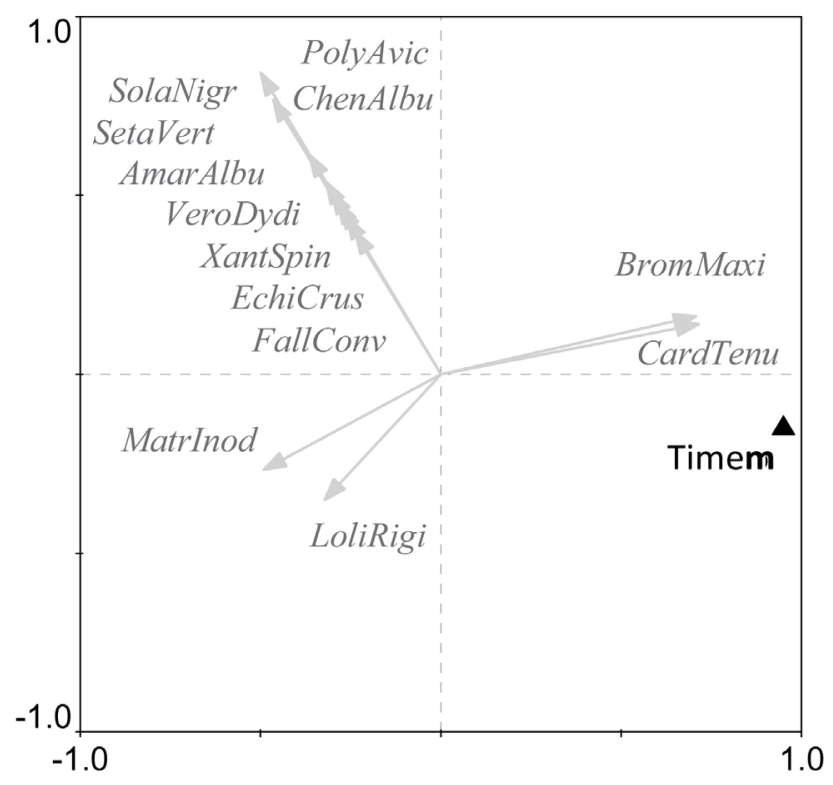

Figure 7. Temporal changes of plant community in the plots of stepping stone are described in this Ordination diagram (redundancy analysis; RDA).

without stepping stone (-SS) (Figure 8) was elucidated using an Ordination diagram (redundancy analysis; RDA). 


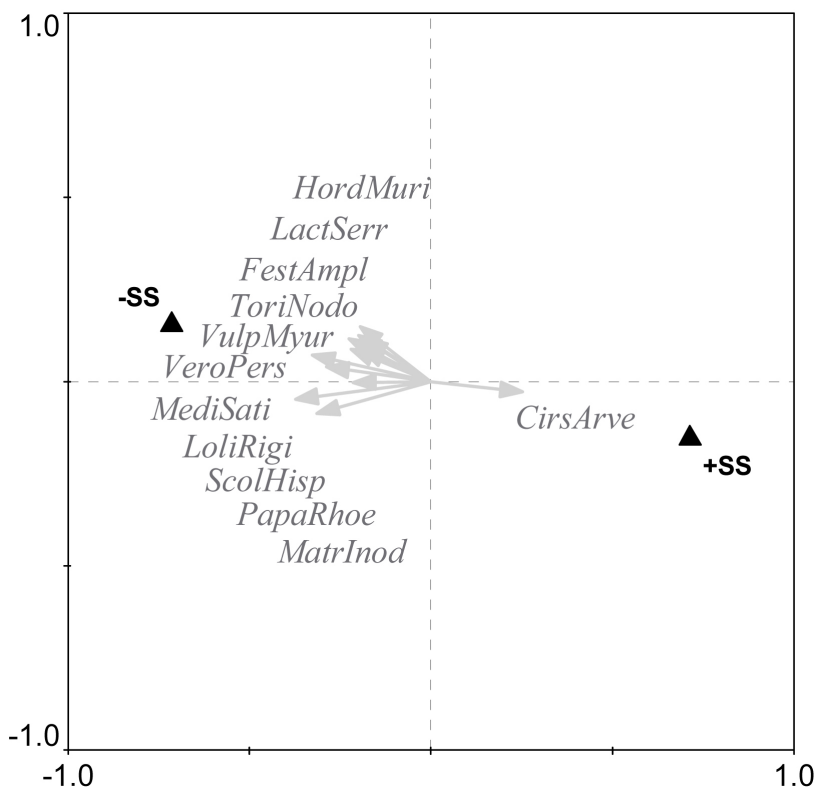

Figure 8. Ordination diagram (redundancy analysis; RDA) showing the response of the colonizing species stepping stone treatments $(+S S)$ without stepping stone $(-S S)$.

\section{Discussion}

\subsection{Annual Performance of Stepping Stone Plots}

Significant decrease of abundance of the sown species at the end of the experimental period was established in stepping stone plots, reaching levels close to $20 \%$ of total cover, whereas, in plots without stepping stone, this percentage remained constant. In both sown treatments, the dominance of sown treatments decreased over time. The total cover of sown species decreased in 2002, independently of stepping stone treatment, however this decrease was more emphasized in the grasses group, even though they were not influenced by the stepping stone treatment.

In the same way, it was noticeable that the annual behaviour of each sown treatment with or without stepping stone was very similar, being greater in HD diversity sown species, due to the combined action of a number of higher sown species, but in general, both treatments followed a similar trend with or without stepping stone. HD-SS and LD-SS presented a light increase during the two last years of experimental period, due to an increase in the cover of sown grasses, and in the same way, there was a decrease of the cover of the other-forbs colonizer species. For that reason, the cover of the otherforbs colonizer species was negatively correlated $(\mathrm{r}=-0.708, P<0.001)$ with the cover of sown grasses.

The increase of sown grasses was more evident in LD-SS plots, not as a result of treatment effect-SS, but of functional replacement of species, resulting from own interactions of competition among species according to nutrients limitation in a spatial small level. This same trends emerged when the behaviour of functional sown groups was analysed, among them, the grasses was the dominant group throughout the whole 
time and in conditions of low performance (at the end of experimental period) there were no favourable conditions for the dominance of other-forbs or legumes in the plant community.

The sown grass $B$. inermis was well established and became dominant removing other colonizer and sown grasses, due to space limitations. This trend was similar to the experiment of Hansson \& Hagelfors [34] and Kosola \& Gross [35] during the secondary succession. For that reason, this specie is the best option for removing other annual grasses. Besides, if the growth of this species is controlled by annual cuts, it is highly likely that Phleum pratense, another sown grass with a good performance, is not going to be removed.

The facilitation of colonization was also currently under consideration to test the effects of vicinity of individual plants. Various plants were found in abandoned agricultural fields, but they differ in their time of first appearance, peak abundance, and length of time the populations persist. In experimental field studies, these species showed differences in their abilities to colonize various types of ground cover [36]. Various studies indicate that initial establishment is the period in which the plant species may be more sensitive to competition; and plant species richness under contrasting traits, may have important implications for management of species diversity [37].

Sowing of later-successional species essentially changed the initial stage of vegetation development on abandoned arable land. Invasion differs from succession. Invasion usually involves species that reach beyond their previous range [24]. However, the basic ecological principles are similar to succession. Invasiveness implies that the specific characteristics of communities to be invaded affect their invisibility.

\subsection{Effect on Species Composition}

A major difference between this study and several other biodiversity experiments [24] [29] [38] is that in this study, no topsoil was removed, no soil sterilization was applied and no hand-weeding was done. The naturally colonizing plants were mainly weedy species from the seed bank resulting from previous agricultural use of the experimental site.

The first axis was mainly determined by time factor, whereas the differentiation of the other axes was due to sown treatments, confirming the opposite trend among the HD (high-diversity seed mixtures of later successional plant species) and NC (natural colonization) with LD (low-diversity seed mixtures of later successional plant species). Figure 5 shows that the abundance of most colonizer species decreased over time, and only increased in a few species, as the colonizer grasses: B. maximus and Festuca arundinaceae, and the other-forbs such as: $T$. villosa and $C$. tenuifolius. This last specie was the only perennial species that dominated in the last phase of the experimental period. This variability can due to the different abundance of the former, and surely also due to other intrinsic feature, such as dispersion ability, or because annuals have not yet germinated in autumn when leaching and uptake begins by perennials and when other species are not present [39]. On the other hand, as soon as functionally different species 
are mixed, e.g. species from different successional stages, effects of differences in traits override any effects of species richness and the relative abundance of different functional groups becomes the meaningful metric to characterise diversity effects [40].

The time explained at a higher rate (Analysis 2), the variability of data when the explained variables were separately taken into account (32\% of total data variability). $B$. maximus and $C$. tenuifolius were the only two species that reached high values in the first axis, which means that their species abundance was increased over time, no matter the sown treatment or stepping stone (Figure 7). In the middle years, Matricaria inodora and Lolium rigidum were the dominant species, whereas the other-forbs group were mostly the dominant species after a year of experimental establishment. The other-forb Cirsium arvense (Analysis 4) was the only species that was positively influenced by the stepping stone (+SS) treatment. The explained variables showed only the $4.7 \%$ of total variability (Figure 8 ).

Similar to the experiment of Leps et al. [2], our results support the hypothesis that plant species diversity may have idiosyncratic effects on soil communities, even though studies on a longer term could reveal time lags in response to changes in composition of plant and the improvement of these communities depend on the stronger competing species [41]. These authors revealed that the sown species were very well spread at close distance, especially $B$. inermis with a clonal growth leaving space for the colonization of new species. The species richness drops due to spreading of competitively strong species and competitive exclusion of subordinate species. It is also clear that the goal of restoration measures is not diversity itself, but diversity of some goal species. Although some arable weed species are considered rare and endangered, their survival is usually dependent on regular ploughing, and they are not able to survive in permanent grassland. Also, many competitively strong weeds are undesirable in the communities (e.g. the danger of further spreading to adjacent arable fields). In reality, the situation is even more complicated-whereas some of the arable weeds are highly undesirable (e.g. Rumex spp., Cirsium arvense), some of the species present in arable field seed bank or invading the arable field spontaneously from adjacent communities are also regular part of the meadow communities, a part of the meadow diversity (and there is no general rule, how to separate the undesirable species from the species we consider part of the meadow biodiversity). However, the decrease of colonizing species in the "strongest LD mixture" is as big and sometimes even bigger (SP) than that in HD. Even so, the number of colonizing species tends to be highest in NC and lowest in HD treatment, regardless of the scale during most of the studied period. Consequently, the convergence appearing in some locations was caused mainly by the spread of the sown species. Nevertheless, there were some species that, despite being abundant in sown plots, never or very seldom spread.

The purpose of most diversity restoration projects is not to improve diversity per se, but to rather enhance the presence and abundance of species that are characteristic of reference or target community. There can be two (not mutually exclusive) goals when sowing grassland species into abandoned fields; firstly to suppress potentially noxious 
arable weeds. The use of $B$. inermis suppress annual noxious grasses and increase the control of other-forb group although these species are also noxious weeds, these may be substituted with another perennial species of the same functional group all through the whole experimental period, as occurs with the other-forb perennial $C$. tenuifolius, which is a strong dominant at the end of experimental period in all sown and unsown plots.

Likewise, it is certainly possible that various species of legumes (M. lupulina, $T$. pratense and T. subterraneum) were facilitated by $P$. pratense, which shared the same disappearance model in the plot where these species were sown; as well as the other-forb such as $P$. lanceolata which also disappeared by space limitations, and provided the dominance of $T$. fragiferum for some years, but only in the presence of this last specie.

As expected, sowing suppressed both the total cover, and the number of naturally-colonizing species. As a result, in most countries total number of species was highest in the natural colonization treatment. This is desirable for restoration, as the community most successful in suppression of noxious weeds will most likely be the most successful in suppression of the desired colonizers.

The first plant species to become established on abandoned arable land are weedy species that are already present in the seed bank [42]. These are opportunists with relatively poor root exploitation capacity [1]. During the initial stage of land abandonment, the initial colonizing plant species are replaced by persistent perennials [34] [35]. If plant propagules reach abandoned arable land by the time the vegetation is dominated by persistent perennials, poor establishment conditions can be crucial constraints of succession to species rich vegetation.

The development of plant communities is always affected by the presence of strong dominants [41] [43] and is often highly idiosyncratic. At locations with invasion potential of the species from a target community nearby, one should be aware that sowing mixtures could suppress desired natural colonization. It seems that highly suppressive mixtures were either the high diversity ones, or the ones composed of strong competitors. However, the presence of a strong competitor in a mixture not only suppresses the colonizers, but also leads to reduced survival of other sown species.

\section{Conclusions}

Our study has demonstrated the restoration effectiveness of species richness at abandoned arable land and may be enhanced by the sowing of late successional species. This handling was successful in achieving the desired composition, with the suppression of noxious arable weeds, especially for colonizer grasses.

Local conditions and species identities affect the suppressive capacity of plant communities towards other species, which complicates the generalization of any relationship between the diversity of communities and their susceptibility to invasions, and should be the most critical factor taking into account the future restoration plans in a dehesa-like woodland, since there are no guarantees that later successional plant species will remain in the environmental features characteristic of this ecosystem. The loss of 
dominance of sown species is without the appropriate management, besides the fact that it will inevitably lead to the convergence of species composition with the proliferation of annual noxious arable weeds.

The use of $B$. inermis suppresses annual noxious grasses and increases the control of other-forb group although these species are also noxious weeds, these may be replaced by another perennial species of the same functional group throughout the whole experimental period, as occurs with the other-forb perennial $C$. tenuifolius, which is a strong dominant at the end of the experimental period in all sown and unsown plots.

\section{Acknowledgements}

The experimental work described was supported by the Framework IV Environment and Climate Programme of the European Commission, contract number ENV4-CT950002. We are indebted to J. Hernández and J. J. Martin for their help.

\section{References}

[1] Grime, J.P. (1997) Biodiversity and Ecosystem Function: The Debate Deepens. Science, 277, 1260-1261. http://dx.doi.org/10.1126/science.277.5330.1260

[2] Leps, J., Brown, V.K., Diaz-Len, T.A., Gormsen, D., Hedlund, K. Kailova, J., Korthals, G.W., Mortimer, S.R., Rodriguez-Barrueco, C., Roy, J., Regina, I.S., van Dijk, C. \& van der Putten, W.H. (2001) Separating the Chance Effect from Other Diversity Effects in the Functioning of Plant Communities. Oikos, 92, 123-134. http://dx.doi.org/10.1034/j.1600-0706.2001.920115.x

[3] Huston, M.A. (1997) Hidden Treatments in Ecological Experiments: Re-Evaluating the Ecosystem Function of Biodiversity. Oecologia, 110, 449-460.

http://dx.doi.org/10.1007/s004420050180

[4] Schlapfer, F., Schmid, B. and Seidl, I. (1999) Expert Estimates about the Effects of Biodiversity on Ecosystem Processes and Services. Oikos, 84, 346-352. http://dx.doi.org/10.2307/3546733

[5] Lawton, J.H., Naeem, S., Thompson, L.J., Hector, A. and Crawley, M.J. (1998) Biodiversity and Ecosystem Function: Getting the Ecotron Experiment in Its Correct Context. Functional Ecology, 12, 848-852

[6] Tilman, D. (1999) The Ecological Consequences of Changes in Biodiversity: A Search for General Principles. Ecology, 80, 1455-1474.

[7] Tilman, D. (1982) Resource Competition and Community Structure. Princeton University Press, Princeton.

[8] Picket, S.T.A. and White, P. (1985) The Ecology of Natural Disturbances and Pach Dynamics. Academic Press, New York.

[9] Connel, J.H. (1978) Diversity in Tropical Rain Forests and Coral Reefs. Science, 199, 13021310. http://dx.doi.org/10.1126/science.199.4335.1302

[10] Huston, M. (1979) A General Hypothesis of Diversity. American Naturalist, 113, 81-101. http://dx.doi.org/10.1086/283366

[11] Belsky, A.J. (1986a) Revegetation of Artificial Disturbances in Grasslands of the Serengueti National Park, Tanzania. II. Five Years of Successional Change. Journal of Ecology, 74, 937952. http://dx.doi.org/10.2307/2260225

[12] Belsky, A.J. (1986b) Revegetation of Artificial Disturbances in Grasslands of the Serengueti 
National Park, Tanzania. I. Colonization of Grazed and Ungrazed Plots. Journal of Ecology, 74, 419-438. http://dx.doi.org/10.2307/2260265

[13] King, T.J. (1977) The Plant Ecology of Ant-Hills in Calcareous Grasslands. I. Patterns of Species in Relation to Ant-Hills in Southern England. Journal of Ecology, 65, 235-256. http://dx.doi.org/10.2307/2259077

[14] Platt, W.J. and Weis, I.M. (1977) Resource Partitioning and Competition within a Guild of Fugitive Prairie Plants. American Naturalist, 111, 479-513. http://dx.doi.org/10.1086/283180

[15] Debussche, M., Escarré, J., Lepart, J., Houssard, C. and Lavorel, S. (1996) Changes in Mediterranean plant Succession: Old-Fields Revisited. Journal of Vegetation Science, 7, 519-526. http://dx.doi.org/10.2307/3236300

[16] Fox, B.J. and Fox, M.D. (1986) Resilience of Animal and Plant Communities to Human Disturbance. In: Dell, B., Hopkins, A.J.M. and Lamont, B.B., Eds., Resilience in Mediterranean-Type Ecosystems, Junk, Dordrecht, 39-64.

http://dx.doi.org/10.1007/978-94-009-4822-8 4

[17] Escarré, J., Houssard, C., Debussche, M. and Lepart, J. (1983) Evolution de la vegetation et du sol après abandon cultural en region méditerranéenne: etude de succession dans les Garrigues du Montpelliérais (France). Acta Oecologica Oecologia Plantarum, 18, 221-239.

[18] Lavorel, S., Lebreton, J.D., Debussche, M. and Lepart, J. (1991) Nested Spatial Patterns in Seed Bank and Vegetation of Mediterranean Old-Fields. Journal of Vegetation Science, 2, 367-376. http://dx.doi.org/10.2307/3235929

[19] Lavorel, S., Lepart, J., Debussche, M., Lebreton, J.D. and, Beffy, J.L. (1994) Small Scale Disturbances and the Maintenance of Species Diversity in Mediterranean Old-Fields. Oikos, 70, 455-473. http://dx.doi.org/10.2307/3545786

[20] Williamson, M. (1996) Biological Invasions. Chapman and Hall, London.

[21] Vilà, M. and Weiner, J. (2004) Are Invasive Plant Species Better Competitors than Native Plant Species?_Evidence from Pair-Wise Experiments. Oikos, 105, 229-238. http://dx.doi.org/10.1111/j.0030-1299.2004.12682.x

[22] Crawley, M. (1990) The Population Dynamics of Plants. Philosophical Transactions of the Royal Society B, 330, 125-140. http://dx.doi.org/10.1098/rstb.1990.0187

[23] Keane, R.M. and Crawley, M.J. (2002) Exotic Plant Invasions and the Enemy Release Hypothesis. Trends in Ecology and Evolution, 17, 164-169.

http://dx.doi.org/10.1016/S0169-5347(02)02499-0

[24] Van der Putten, W.H., Mortimer, S.R., Hedlund, K., Van Dijk, C., Brown, V.K., Leps, J., Rodriguez-Barrueco, C., Roy, J., Len, T.A.D., Gormsen, D., Korthals, G.W., Lavorel, S., Regina, I.S. and Smilauer, P. (2000) Plant Species Diversity as a Driver of Early Succession in Abandoned Fields: A Multi-Site Approach. Oecologia, 124, 91-99.

http://dx.doi.org/10.1007/s004420050028

[25] Leps, J., Dolezal, J., Bezemer, T.M., Brown, V.K., Hedlund, K., Igual, M., Jorgensen, H.B., Lawson, C.S., Mortimer, S.R., Peix Geldart, A., Rodriguez Barrueco, C., Santa Regina, I., Smilauer, P. and van der Putten, W.H. (2007) Long-Term Effectiveness of Sowing High and Low Diversity Seed Mixtures to Enhance Plant Community Development on Ex-Arable Fields. Applied Vegetation Science, 10, 97-110. http://dx.doi.org/10.1658/1402-2001(2007)10[97:LEOSHA]2.0.CO;2

[26] Hedlund, K., Santa Regina, I., van der Putten, W.H., Leps, J., Díaz, T., Korthals, G.W., Lavorel, S., Brown, V.K., Gormsen, D., Mortimer, S.R., Barrueco, C.R., Roy, J., Smilauer, P., Smilauerova, M. and Van Dijk, C. (2003) Plant Species Diversity, Plant Biomass and Res- 
ponses of the Soil Community on Abandoned Land across Europe: Idiosyncracy or AboveBelowground Time Lags. Oikos, 103, 45-58. http://dx.doi.org/10.1034/j.1600-0706.2003.12511.x

[27] Naeem, S., Knops, J.M.H., Tilman, D., Howe, K.M., Kennedy, T. and Gale, S. (2000) Plant Diversity Increases Resistance to Invasion in the Absence of Covarying Extrinsic Factors. Oikos, 91, 97-108. http://dx.doi.org/10.1034/j.1600-0706.2000.910108.x

[28] Bullock, J.M., Pywell, R.F., Burke, M.J.W. and Walker, K.J. (2001) Restoration of Biodiversity Enhances Agricultural Production. Ecology Letters, 4, 185-189. http://dx.doi.org/10.1046/j.1461-0248.2001.00215.x

[29] Hector, A., Schmid, B., Beierkuhnlein, C., Caldeira, M.C., Diemer, M., Dimitrakopoulos, P.G., Finn, J.A., Freitas, H., Giller, P.S., Good, J., Harris, R., Hogberg, P., Huss-Danell, K., Joshi, J., Jumpponen, A., Korner, C., Leadley, P.W., Loreau, M., Minns, A., Mulder, C.P.H., O’Donovan, G., Otway, S.J., Pereira, J.S., Prinz, A., Read, D.J., Scherer-Lorenzen, M., Schulze, E.D., Siamantziouras, A.S.D., Spehn, E.M., Terry, A.C., Troumbis, A.Y., Woodward, F.I., Yachi, S. and Lawton, J.H. (1999) Plant Diversity and Productivity Experiments in European Grasslands. Science, 286, 1123-1127. http://dx.doi.org/10.1126/science.286.5442.1123

[30] Pakeman, R.J., Pywell, R.F. and Wells, T.C.E. (2002) Species Spread and Persistence: Implications for Experimental Design and Habitat Re-Creation. Applied Vegetation of Science, 5, 76-86.

[31] Pfisterer, A.B., Joshi, J., Schmid, B. and Fischer, M. (2004) Rapid Decay of Diversity-Productivity Relationships after Invasion of Experimental Plant Communities. Basic \& Applied Ecology, 5, 5-14. http://dx.doi.org/10.1078/1439-1791-00215

[32] FAO (1989) The Revised Legend: FAO/UNESCO: Soil Map of the World. FAO, Rome

[33] Ter Braak, C.J.F. and Smilauer, P. (1998) CANOCO Release 4. Reference Manual and Users Guide to CANOCO for Windows: Software for Canonical Community Ordination. Microcomputer Power, Ithaca, USA.

[34] Hansson, M. and Hagelfors, H. (1998) Management of Permanent Set-Aside on Arable Land in Sweden. Journal of Applied Ecology, 35, 758-771.

http://dx.doi.org/10.1046/j.1365-2664.1998.355350.x

[35] Kosola, K.R. and Gross, K.L. (1999) Resource Competition and Suppression of Plants Colonizing Early Successional Old Fields. Oecologia, 118, 69-75. http://dx.doi.org/10.1007/s004420050704

[36] Gross, K.L. and Werner, P.A. (1982) Colonizing Abilities of "Biennial” Plant Species in Relation to Ground Cover: Implications for Their Distributions in a Successional Serie. Ecology, 63, 921-932. http://dx.doi.org/10.2307/1937232

[37] Foster, B.L. and Gross, K.L. (1998) Species Richness in a Successional Grassland: Effects of Nitrogen Enrichment and Plant Litter. Ecology, 79, 2593-2602. http://dx.doi.org/10.1890/0012-9658(1998)079[2593:SRIASG]2.0.CO;2

[38] Hooper, D.U. and Vitousek, P.M. (1997) The Effects of Plant Composition and Diversity on Ecosystem Processes. Science, 277, 1302-1305. http://dx.doi.org/10.1126/science.277.5330.1302

[39] Marks, P.L. and Bormann, F.H. (1972) Revegetation Following Forest Cutting: Mechanisms for Return to Steady-State Nutrient Cycling. Science, 176, 914-923.

http://dx.doi.org/10.1126/science.176.4037.914

[40] Nijs, L. and Roy, J. (2000) How Important Are Species Richness, Species Evenness and Interspecific Differences to Productivity? A Mathematical Model. Oikos, 88, 57-66. 
http://dx.doi.org/10.1034/j.1600-0706.2000.880107.x

[41] Clarke, P.J., Latz, P.K. and Albrecht, D.E. (2005) Long-Term Changes in Semi-Arid Vegetation: Invasion of an Exotic Perennial Grass Has Larger Effects than Rainfall Variability. Journal of Vegetation Science, 16, 237-248.

http://dx.doi.org/10.1111/j.1654-1103.2005.tb02361.x

[42] Bekker, R.M., Bakker, J.P. and Thompson, K. (1997) Dispersal of Plant Species in Time and Space: Can Nature Development Rely on Soil Seed Banks and Dispersal? 6 th IALE Conference on Species Dispersal and Land Use Processes, University of Ulster, 9-11 September 1997, 247-255.

[43] Prach, K., Pyšek, P. and Bastl, M. (2001) Spontaneous Vegetation Succession in HumanDisturbed Habitats: A Pattern across Seres. Applied Vegetation Science, 4, 83-88.

http://dx.doi.org/10.1111/j.1654-109X.2001.tb00237.x

\section{Submit or recommend next manuscript to SCIRP and we will provide best service for you:}

Accepting pre-submission inquiries through Email, Facebook, LinkedIn, Twitter, etc. A wide selection of journals (inclusive of 9 subjects, more than 200 journals)

Providing 24-hour high-quality service

User-friendly online submission system

Fair and swift peer-review system

Efficient typesetting and proofreading procedure

Display of the result of downloads and visits, as well as the number of cited articles

Maximum dissemination of your research work

Submit your manuscript at: http://papersubmission.scirp.org/ 